\title{
Parasite component community of smalltooth sawfish off Florida: diversity, conservation concerns, and research applications
}

\author{
Micah D. Bakenhaster ${ }^{1, *}$, Stephen A. Bullard ${ }^{2}$, Stephen S. Curran ${ }^{3}$, \\ Delane C. Kritsky ${ }^{4}$, Erin H. Leone ${ }^{5}$, Lauren K. Partridge ${ }^{1}$, Carlos F. Ruiz ${ }^{2}$, \\ Rachel M. Scharer ${ }^{6}$, Gregg R. Poulakis ${ }^{6}$
}

${ }^{1}$ Fish and Wildlife Research Institute, Florida Fish and Wildlife Conservation Commission, St. Petersburg, Florida 33701, USA

${ }^{2}$ Aquatic Parasitology Laboratory, School of Fisheries, Aquaculture, and Aquatic Sciences, College of Agriculture, Auburn University, Auburn, Alabama 36849, USA

${ }^{3}$ Gulf Coast Research Laboratory, Division of Coastal Sciences, University of Southern Mississippi, Ocean Springs, Mississippi 39564, USA

${ }^{4}$ Health Education Program, School of Health Professions, Idaho State University, Pocatello, Idaho 83209, USA

${ }^{5}$ Center for Biostatistics and Modeling, Fish and Wildlife Research Institute, Florida Fish and Wildlife Conservation Commission, Gainesville, Florida 32601, USA

${ }^{6}$ Fish and Wildlife Research Institute, Florida Fish and Wildlife Conservation Commission, Charlotte Harbor Field Laboratory, Port Charlotte, Florida 33954, USA

\begin{abstract}
Compared with that of other charismatic elasmobranchs, the component community of metazoan parasites infecting endangered smalltooth sawfish Pristis pectinata is exceedingly poorly characterized: adults of Dermophthirioides pristidis and Neoheterocotyle inpristi (ectoparasitic flatworms of skin and gill, respectively) were the only confirmed parasites prior to the description, based on specimens reported herein, of Mycteronastes caalusi. Our opportune and directed parasitological examinations of 290 smalltooth sawfish (277 live inspections; 13 necropsies; 671 to $2640 \mathrm{~mm}$ stretch total length) in south Florida coastal waters revealed at least 8 species of Platyhelminthes, 9 of Arthropoda, 4 of Annelida, and 1 of Nematoda. This collection includes representatives of an undescribed species of Aporocotylidae (Digenea) and myriad new host records, considerably updating and advancing our understanding of smalltooth sawfish symbionts. We also confirm that $D$. pristidis and $N$. inpristi are extant and propose $D$. pristidis as a reliable biological tag. Some of these parasites are evidently highly host-specific and so vulnerable to extinction.
\end{abstract}

KEY WORDS: Pristis pectinata - Dermophthirioides pristidis · Coextinction · Parasite conservation · Biological indicators $\cdot$ Biological tags

\section{INTRODUCTION}

The intrinsic value of the parasites of the endangered (see NMFS 2003) smalltooth sawfish Pristis pectinata Latham 1794 has been given little attention; nevertheless, sawfish parasites are a threatened component of evolutionary history, they may impart

\footnotetext{
*Corresponding author: micah.bakenhaster@myfwc.com
}

health benefits to their hosts, and they may have a practical role to play in conservation efforts. Coextinction, the demise of dependent affiliate organisms resulting from extinction of their host species, was proposed by Dunn et al. (2009) as 'the most insidious threat to global biodiversity.' This idea has merit, of course, because we are unlikely to know that some-

(C) The authors 2018. Open Access under Creative Commons by Attribution Licence. Use, distribution and reproduction are unrestricted. Authors and original publication must be credited. 
thing is gone if we do not know it existed, and, while the diversity of metazoan parasites is undoubtedly very high (Windsor 1998), it is also difficult to measure. This is partly because not all hosts have been described (Windsor 1998, Dobson et al. 2008), but also because parasites, even those infecting intensively studied fishes like the smalltooth sawfish, are inherently challenging to investigate given their typically small size and cryptic life habits. Attention to parasites has largely focused on their role as agents of disease, but a full understanding of their complex ecological function requires broader consideration (Wood \& Johnson 2015). They are, in fact, an integral component of a healthy ecosystem and can serve as biological indicators of host and environmental health (Marcogliese 2005, Dougherty et al. 2016). Some may reduce transmission rates of more pathogenic species (Johnson et al. 2013), act as contaminant sinks (Sures 2003), indicate host ancestry, or serve as biological tags (Whiteman \& Parker 2005).

Smalltooth sawfish parasites are largely unstudied. Hargis (1955) described the monogenoid Neoheterocotyle inpristi Hargis, 1955 (Monocotylidae) from the gill of an unspecified sawfish (Pristis sp.) from the northeastern Gulf of Mexico off Franklin County, Florida. Cheung \& Nigrelli (1983) rediscovered this parasite (as $N$. ruggierii; see synonymy of Chisholm 1994) and described the skin-infecting monogenoid Dermophthirioides pristidis Cheung \& Nigrelli 1983 (Microbothriidae) from smalltooth sawfish collected in the Florida Keys. There are a few, brief mentions of the isopods Livoneca ovalis (Say, 1818) (sometimes as Lironeca ovalis) and Nerocila acuminata Schiödte \& Meinert, 1881 (Cymothoidae) infecting unspecified sawfish (Moreira \& Sadowsky 1978); however, empirical data are wanting, and a single listing from a venerable monograph on isopods (Richardson 1905) seems the likely source of later listings until the present study. Hutton (1964) anecdotally reported metacercariae of the trematode Scaphanocephalus expansus (Creplin, 1842) as a parasite of the smalltooth sawfish from the eastern Gulf of Mexico near Tarpon Springs, Florida. No details were provided, however, and voucher specimens were apparently not deposited, so verification is not possible. That no other published record exists, prior to the very recent description of Mycteronastes caalusi Kritsky, Bullard, Bakenhaster, Scharer \& Poulakis, 2017 (Kritsky et al. 2017), underscores the importance of any new parasitological data from smalltooth sawfish.

Researchers of the Florida Fish and Wildlife Conservation Commission's Fish and Wildlife Research Institute (FWRI) routinely monitor the population of the smalltooth sawfish in the Charlotte Harbor estuarine system, on the Gulf of Mexico coast of Florida, including the tidal reaches of the Peace and Caloosahatchee rivers. This activity provides opportunities for rapid canvassing of hosts for ectoparasites. Also, FWRI biologists conduct necropsies on opportunely obtained sawfish carcasses identified through solicited public reports of mortalities in Florida waters. Since 2004, parasitological data and specimens have been collected during this sampling, and they serve as the basis for this report. Here, we provide preliminary data for bringing attention to the previously unknown diversity of parasites infecting smalltooth sawfish, and we propose that they are useful in efforts to conserve their host.

\section{MATERIALS AND METHODS}

Beginning in 2004, parasites were collected from living and dead smalltooth sawfish Pristis pectinata. Ectoparasites were taken primarily from live hosts sampled during routine population monitoring in the Charlotte Harbor estuarine system (Poulakis et al. 2011). Sampling was conducted primarily from February through September, so effort was less in the fall and winter. Smalltooth sawfish were caught in gill nets and seines and kept in a flooded net well or tub until they were measured, tagged, and examined before release. Though monitoring is ongoing, this report covers ectoparasites collected from live hosts for the period 1 March 2004 through 15 September 2014. Additional parasitological surveys were conducted on freshly dead smalltooth sawfish carcasses reported by citizens via FWRI's sawfish hotline (Seitz \& Poulakis 2002). Material from dead hosts was recovered from various locations in south Florida from 15 January 2010 through 2 July 2016, and those parasites are also included here.

During the 12 yr study period, the protocol for parasitological field evaluations evolved from one of passive observation to more active canvassing by field analysts, who became increasingly more adept at detecting parasites. Representative parasite specimens were removed with forceps and placed in 50\% isopropyl alcohol, 70 to $95 \%$ ethanol, or $10 \%$ formalin, either in the field or, after being retained alive in containers of seawater placed on ice for the duration of a sampling day, in the laboratory.

By 2013, sampling methods included routine gross visual inspections, conducted by experienced analysts, of dorsal and ventral skin, fins, eyes, gill slits, spiracle openings, and mouth. To minimize handling 
time of hosts, a few captured fish were not checked for parasites, and not all parasites noted in the field were evaluated in the laboratory; but with the exception of some specimens of Dermophthirioides pristidis, only parasites with laboratory-confirmed identifications are reported here. Beginning in 2013, specimens of $D$. pristidis were always recorded and, with one exception, counted in the field, whether or not voucher specimens were retained.

Specimens used for scanning electron microscopy were post-fixed in $1 \%$ osmium tetroxide, dehydrated through a graded ethanol series, critical-point-dried, and sputter-coated with gold. They were examined on a Hitachi S-3400N scanning electron microscope (SEM). A photomicrograph of $D$. pristidis was taken with an Olympus DP72 digital camera attached to a Nikon SMZ1500 stereomicroscope. Photomicrographs for specimens of Mycteronastes caalusi and Aporocotylidae sp. were prepared with an Olympus BX-51 equipped with differential interference contrast (Nomarski) optics and an Olympus DP 71 digital camera.

Smalltooth sawfish carcasses were transported on ice (Fig. 1) to the FWRI Charlotte Harbor Field Laboratory in Port Charlotte, where necropsies were conducted. In the case of one specimen, we received only freshly frozen organs. Opportune parasitological evaluations were included in necropsies only of recently dead hosts (i.e. those emitting little or no odor of decay, though most host specimens had died many hours prior to necropsy). Parasites recovered from carcasses were isolated, fixed, and identified, in part, at the FWRI in St. Petersburg. Further identifications were made at Idaho State University, Auburn University, and the University of Southern Mississippi.

When gill, olfactory organ, and internal parasitological evaluations could be conducted on fresh material, parasites were visually confirmed as dead (not moving) prior to fixation. After isolation and rinsing, fresh specimens for morphological study were placed directly into $5 \%$ neutral buffered formalin, and specimens for future molecular evaluation (not included in this report) were preserved in 95\% ethanol. When time constraints required that organs be fixed before parasite examinations, the organs were cut open (gastrointestinal tract and heart) or placed directly (gills) into containers and doused with 70 to $90^{\circ} \mathrm{C}$ tap water to heat kill any helminths that might have been alive. Immediately following hot water, $10 \%$ neutral buffered formalin was added to containers to double the volume of liquid so that any parasites would be fixed in roughly $5 \%$ formalin.
In analyses of prevalence and intensity of $D$. pristidis, we eliminated data collected before 2013 and an additional 11 screenings from 2013 through 2014 for which voucher specimens were not collected and for which field notes were insufficient for us to confidently determine presence or absence at the time of analysis. One individual was captured and screened on 4 separate occasions, but the first 3 screenings took place during a 1 mo period, so only the first and fourth screenings were included for analysis. To evaluate any effects of season (winter: December to February; spring: March to May; summer: June to August; fall: September to November), host size (stretch total length, defined as the maximum length from tip of rostrum to tip of caudal fin; STL), and sex on prevalence ( $\%$ of hosts infected) and intensity (number of worms present on a given infected host), we used generalized linear mixed models (SAS

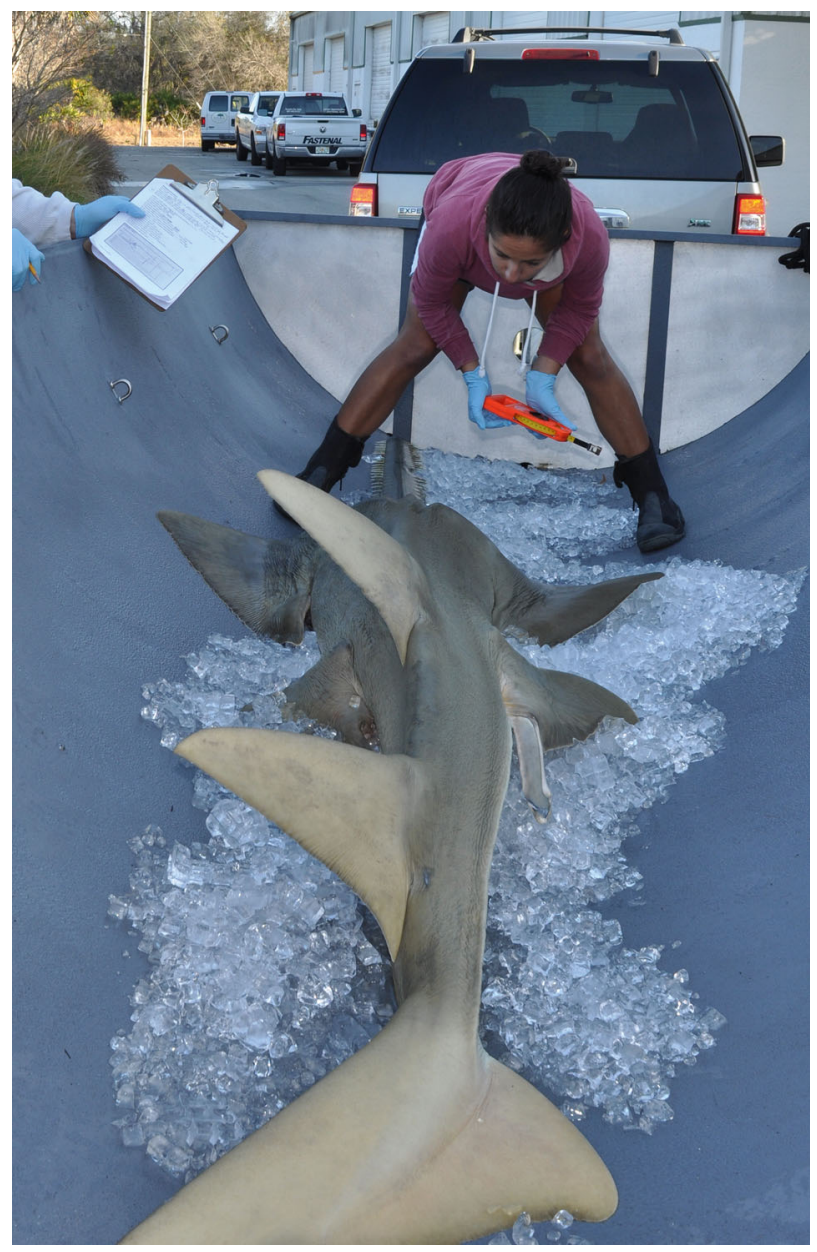

Fig. 1. Biologist examining the carcass of a smalltooth sawfish Pristis pectinata collected in south Florida and transported on ice in a recovery trailer to the Fish and Wildlife Research Institute Charlotte Harbor Field Laboratory for necropsy 
V9.4). Because we collected relatively few samples in fall $(n=5)$ and winter $(n=3)$, we combined samples caught in these seasons for analysis. We assumed a binomial distribution for prevalence (yes/no infected) and a negative binomial distribution for intensity (i.e. number of $D$. pristidis). We initially included a random effect to account for multiple captures of the same tagged fish, but that covariance was estimated at zero in both models and so this random effect was dropped.

\section{RESULTS}

We documented findings from 336 screenings for ectoparasites on 290 specimens of smalltooth sawfish Pristis pectinata ( $\mathrm{n}=277$ living and 13 recently dead) ranging in size from 671 to $2640 \mathrm{~mm}$ STL (mean = $1230 \mathrm{~mm}$ ). Postmortem screenings for gill and internal parasites were conducted on 8 of the freshly dead hosts. In total, we collected at least 22 species of internal and external parasites belonging to 4 phyla (Table 1). Complete taxonomic evaluations of parasites are still in progress, and, as they are completed, voucher specimens will be deposited in the National Invertebrate Zoology Collection of the National Museum of Natural History (Smithsonian Institution, Washington, DC).

We observed few instances of parasite-associated lesions. There were occasionally patches of bluish discoloration on host skin with apparent scale loss (determined by gross visual and tactile examination). These were anecdotally associated with relatively intense infections by Dermophthirioides pristidis and

Table 1. Summary of parasites observed infecting smalltooth sawfish Pristis pectinata in south Florida from 2004 through July 2016, with their intensity range and infection sites

\begin{tabular}{|c|c|c|c|}
\hline Parasite taxon & $\begin{array}{l}\text { No. of hosts } \\
\text { infected }\end{array}$ & $\begin{array}{l}\text { Intensity range } \\
\text { (no. of hosts with counts) }\end{array}$ & Infection sites \\
\hline \multicolumn{4}{|l|}{ Monogenoidea (Platyhelminthes) } \\
\hline Dermophthirioides pristidis & 97 & $1->50(88)$ & Dorsal skin, fins, rostrum \\
\hline Neoheterocotyle inpristi & 3 & $2-12(3)$ & Gill \\
\hline Mycteronastes caalusi & 1 & $>60(1)$ & Olfactory sac \\
\hline \multicolumn{4}{|l|}{ Digenea (Platyhelminthes) } \\
\hline Hemiuroidea sp. & 2 & $1(2)$ & Stomach \\
\hline Hemiuridae sp. (Lecithochiriinae) & 1 & $3(1)$ & Stomach \\
\hline Didymozoidae sp. (larvae) & 2 & $1(2)$ & Heart \\
\hline Aporocotylidae sp. (undescribed) & 1 & $1(1)$ & Heart \\
\hline \multicolumn{4}{|l|}{ Cestoda (Platyhelminthes) } \\
\hline Cestoda sp. & 5 & - & Spiral valve \\
\hline \multicolumn{4}{|l|}{ Hirudinea (Annelida) } \\
\hline Branchellion torpedinis & 6 & $1-2(6)$ & $\begin{array}{l}\text { Fins, clasper, mouth, near gill slits, } \\
\text { spiracle, dorsal skin }\end{array}$ \\
\hline Branchellion ravenelii & 16 & $1-5(16)$ & Near gill slits \\
\hline Heptacyclus philothermus & 1 & $1(1)$ & Skin \\
\hline Stibarobdella macrothela (immature) & 2 & $1-3(2)$ & Skin \\
\hline \multicolumn{4}{|l|}{ Copepoda (Arthropoda) } \\
\hline Pandarus sp. & 8 & $1-14(6)$ & Fins \\
\hline Perissopus sp. & 1 & $1(1)$ & Not recorded \\
\hline Lepeophtheirus sp. & 3 & $1(3)$ & Spiracle, mouth \\
\hline Caligus sp. & 1 & $1(1)$ & Dorsal skin \\
\hline Eudactylina sp. & 2 & $2-4(2)$ & Gill \\
\hline \multicolumn{4}{|l|}{ Branchiura (Arthropoda) } \\
\hline Argulus sp. & 2 & $1-2(2)$ & Ventral skin \\
\hline \multicolumn{4}{|l|}{ Isopoda (Arthropoda) } \\
\hline Livoneca sp. (juvenile) & 1 & $1(1)$ & Spiracle \\
\hline Nerocila acuminata (male) & 1 & $1(1)$ & Skin \\
\hline Aegidae sp. & 1 & $1(1)$ & Gill \\
\hline \multicolumn{4}{|l|}{ Nematoda } \\
\hline Ascaridoidea sp. (larvae) & 1 & $1(1)$ & Gastrointestinal tract \\
\hline
\end{tabular}


consistent with other lesions caused by related skin parasites (Microbothriidae) of elasmobranchs (Poynton et al. 1997, Bullard et al. 2000, Young et al. 2013). Occasionally, smalltooth sawfish specimens presented with lesions associated with a single specimen each of the leech Branchellion torpedinis Savigny, 1822. Grossly, affected skin appeared red and swollen, or even ulcerous. Often these leech-associated lesions occurred on the dorsal skin (e.g. posterior to 1st dorsal fin, caudal peduncle), one specimen was attached around the spiracle aperture, and two were observed on claspers (Fig. 2). One host with an infected clasper was captured 3 times. In the first evaluation of that specimen (16 January 2007), no leech was observed but the clasper exhibited reddening and swelling. During the first recapture (9 February 2007), a specimen of B. torpedinis was observed attached to the affected clasper, the swelling was noticeably more severe than it had been earlier, and the reddened area had expanded to include the skin at the base of the pelvic fin. We removed the leech, and when the fish was again captured (13 March 2007), substantial healing had occurred. Similarly, the leech attached to the lesioned spiracle was removed, and when the host was recaptured about 2 mo later, the lesion had apparently completely healed. No smalltooth sawfish collected post-mortem had any internal or external lesions that could be readily attributed to metazoan parasites.

Ectoparasites were generally observed at relatively low prevalence and intensity throughout the study period, but $D$. pristidis was a notable exception: 98 infections were documented over the entire study period, with only 1 misidentification of 355 voucher specimens evaluated in the laboratory. For sampling in 2013 and 2014, we observed infections of D. pristidis on 51 of $80(64 \%)$ field evaluations. These 80 captures represented 69 unique smalltooth sawfish, of which 47 were infected on at least 1 capture occasion $(68 \% ; 95 \%$ CI: 79.1 to 57.3$)$. Of the 9 smalltooth sawfish that were sampled multiple times, 2 were infected each time $(22 \%), 4$ were negative at first capture but subsequently found to be infected (44\%), and 3 were infected at first capture but subsequently found to be negative (33\%). From 2013 through 2014, intensities ranged from 1 to $>50$ individuals. Mean intensity was 10.16 in the 50 evaluations that included exact counts.

Infections of $D$. pristidis were documented yearround and on male and female smalltooth sawfish of all sampled ages (lengths). Host sex had no effect on prevalence $\left(F_{1,75}=1.02, \mathrm{p}=0.340\right)$ or intensity $\left(F_{1,46}=2.36, \mathrm{p}=0.131\right)$. There were, however, effects of both season $\left(F_{2,76}=5.55, \mathrm{p}=0.006\right)$ and host size $\left(F_{1,76}=8.46, \mathrm{p}=0.005\right)$ on prevalence (Fig. 3$)$. Prevalence was highest during the spring, and likelihood of infection increased with host size. Only 3 infected specimens had intensity counts for $D$. pristidis during the fall/winter, so this season combination was removed from the intensity analysis. There was no difference in intensity between the spring and summer seasons $\left(F_{1,46}=0.57, \mathrm{p}=0.455\right)$, but intensity did increase with size $\left(F_{1,46}=10.52, \mathrm{p}=\right.$ 0.002) (Fig. 4).

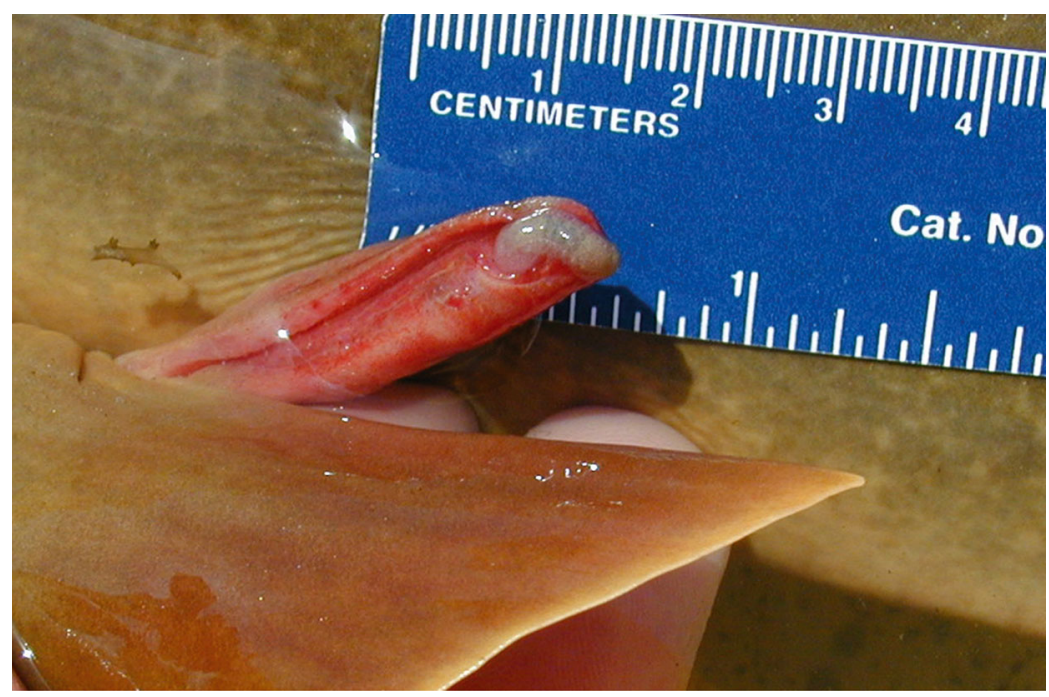

Fig. 2. Reddened and swollen left clasper of a smalltooth sawfish Pristis pectinata infected by the leech Branchellion torpedinis, visible at the distal end of the clasper

\section{DISCUSSION}

As parasites deteriorate rapidly after their host dies and because we sampled ectoparasites from live hosts frequently and endoparasites from dead hosts only, the endoparasite specimens were generally fewer in number, of lower quality, and likely underrepresented in terms of species diversity. Nevertheless, this study increased the number of parasites reported from smalltooth sawfish by 18 taxa.

Both cymothoid isopod species represented in our collections have previously been reported to infect 'sawfish' off North America as per Richardson (1905), who erroneously identified the host as Pristis semisagittatus, appar- 


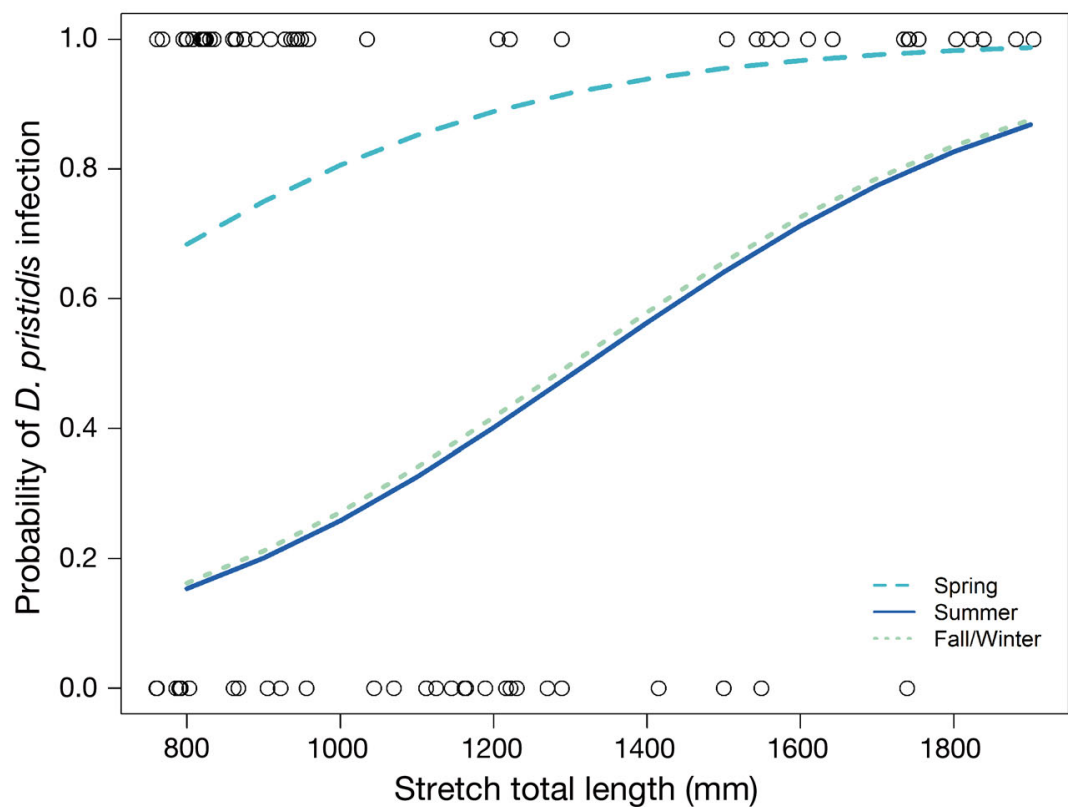

Fig. 3. Seasonal prevalence of Dermophthirioides pristidis relative to stretch total length (STL) of host, smalltooth sawfish Pristis pectinata, collected in south Florida. Fall and winter were combined due to small sample size. Open circles represent host specimens observed to be infected (1.0) and uninfected (0.0) at a given STL; lines are model-predicted prevalence for each season at a given STL

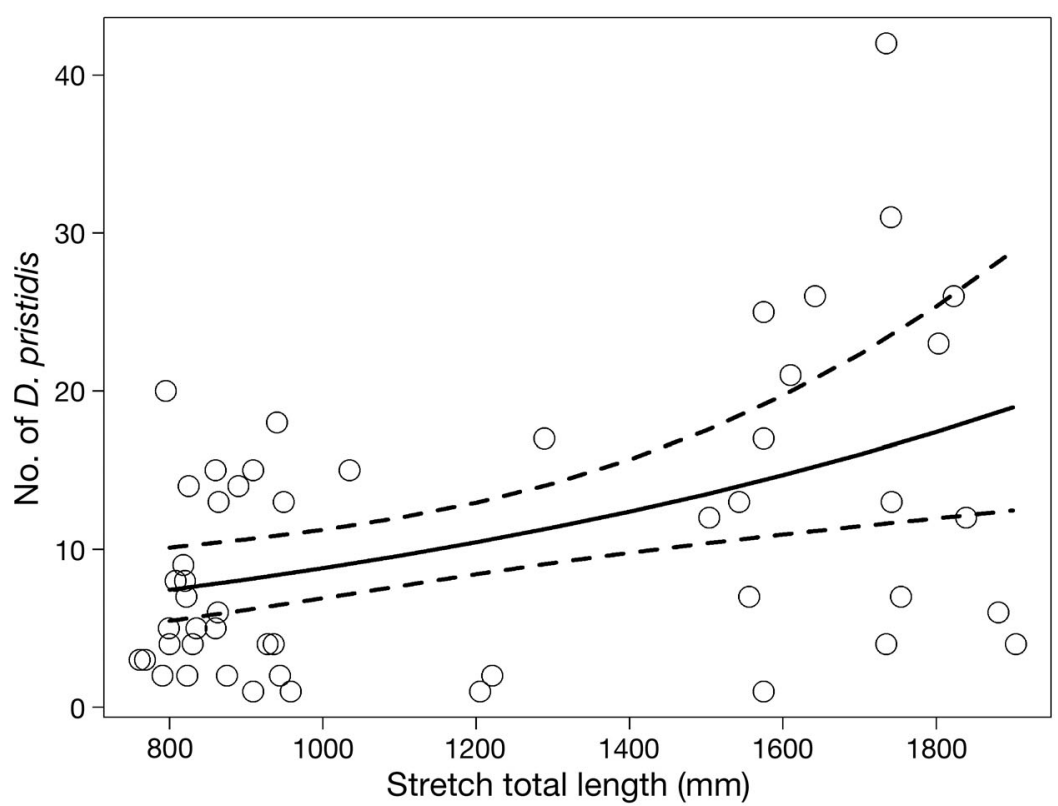

Fig. 4. Intensity of Dermophthirioides pristidis relative to stretch total length (STL) of host, smalltooth sawfish Pristis pectinata, collected in south Florida. Solid curve is the model-predicted intensity at a given STL; dashed curves represent $95 \%$ confidence intervals

ently referring to the IndoPacific species, $P$. semisagittatus (Shaw, 1804) (now Anoxypristis cuspidata (Latham, 1794) (see van Oijen et al. 2007). Poulakis et al. (2010) previously identified our single juvenile speci- men of Livoneca sp. as Livoneca redmanii Leach, 1818 (per Bakenhaster 2004) but the discrepancy is based on nomenclatural confusion rather than differing interpretations of diagnostic characters. In his major revision of the genus, Bruce (1990) considered both Livoneca ovalis and Lironeca ovalis to be junior synonyms to Livoneca redmanii, but Bunkley-Williams et al. (1998) and Williams \& Bowman (1994) argued with merit that Lironeca ovalis was the valid name for the only species of Livoneca (or Lironeca) that ranges in the northern Gulf of Mexico. Further, cryptic species may range there, as suggested by the occurrence of 2 manca morphotypes in broods taken from different females (Bakenhaster 2004). Considering these factors, it seems prudent to avoid assigning this specimen to a species and to use the generic spelling placed on the International Commission on Zoological Nomenclature's (ICZN) Official List of Generic Names in Zoology (see ICZN 1996). The single male specimen of the isopod Nerocila acuminata Schiödte \& Meinert, 1881 (per diagnosis provided by Brusca 1978, 1981) from our collections represents a euryzenous species.

Both stomach-infecting digenean species from our collections were hemiuroids, and 2 specimens could be further identified as members of Lecithochiriinae, and probably belonged to either Plicatrium Manter \& Pritchard, 1960 or Lecithochirium Lühe, 1901. Additional, high quality specimens might allow identification of these species. Members of this group are typically specialized parasites of teleosts and have been considered opportunistic in elasmobranchs (i.e. incidental associations occur, but they do not represent long-term parasitological relationships on an evolutionary scale) (Bray \& Cribb 2003).

In our collections, the poor condition of fragmented cestodes from the spiral valve will likely preclude the possibility of further morphological identification using these specimens. Similarly, 1 ascaridoid nema- 
tode is in poor condition and, like 2 heart-infecting didymozoids, it is a larval form and further identification was not practicable.

None of the leeches are host-specific (per diagnoses and ecological information in Sawyer et al. 1975). Our observation that the leech Branchellion ravenelii (Girard, 1850) was always attached in and around the gill slits is novel and contrasts with the observed habits of its less site-specific congener $B$. torpedinis Savigny 1882. In the case of the leech Heptacyclus philothermus (Sawyer, Lawler \& Overstreet, 1975), our specimen was in poor condition and some diagnostic features (eyespots or characteristic dorsal pigmentation) could not be confirmed. All other leeches known to range in the region were ruled out by the absence of branchia, tubercles, and pulsatile vesicles and by the shape of the caudal sucker. Our specimens of Stibarobdella macrothela (Schmarda, 1861) were immature, so our identification is tentative, but they possessed a rough tegument with rounded, wart-like tubercles that are unique among the species occurring in the Gulf of Mexico. It is a wide-ranging, generalist parasite of elasmobranchs. The species also infects carcharhinid sharks in the Gulf of Mexico, tiger sharks Galeocerdo cuvier (Péron \& Lesueur, 1822) off Hawaii, and various other sharks off Baja, California (S. S. Curran unpubl. data).

Among the copepod species, our collection of Pandarus sp. is relatively large, with representatives of various ages, but individuals are morphologically similar to both P. floridanus and P. sinuatus (per diagnoses in Cressey 1967). Pigmentation patterns are important in distinguishing the species, but in our samples the degree of pigmentation varies among specimens, apparently increasing with age, so additional microscopic examinations of appendages and comparison with original descriptions and type material are needed. Species-level identification of the other copepods will require more detailed examination and possibly the collection of additional specimens.

Two monogenoid species previously known to infect smalltooth sawfish, Dermophthirioides pristidis (Fig. 5) and Neoheterocotyle inpristi (Fig. 6) were shown to be extant in our sampling area, and highquality specimens allowed for examination with a SEM. This examination provided new morphological information about the dorsal surface of $D$. pristidis, which is densely covered in papillae of undetermined function (Fig. 5C), and detailed 3-dimensional imagery of the haptoral structure of $N$. inpristi. A third monogenoid, Mycteronastes caalusi (Fig. 7), was described as a new species (Kritsky et al. 2017) while the current manuscript was in review.
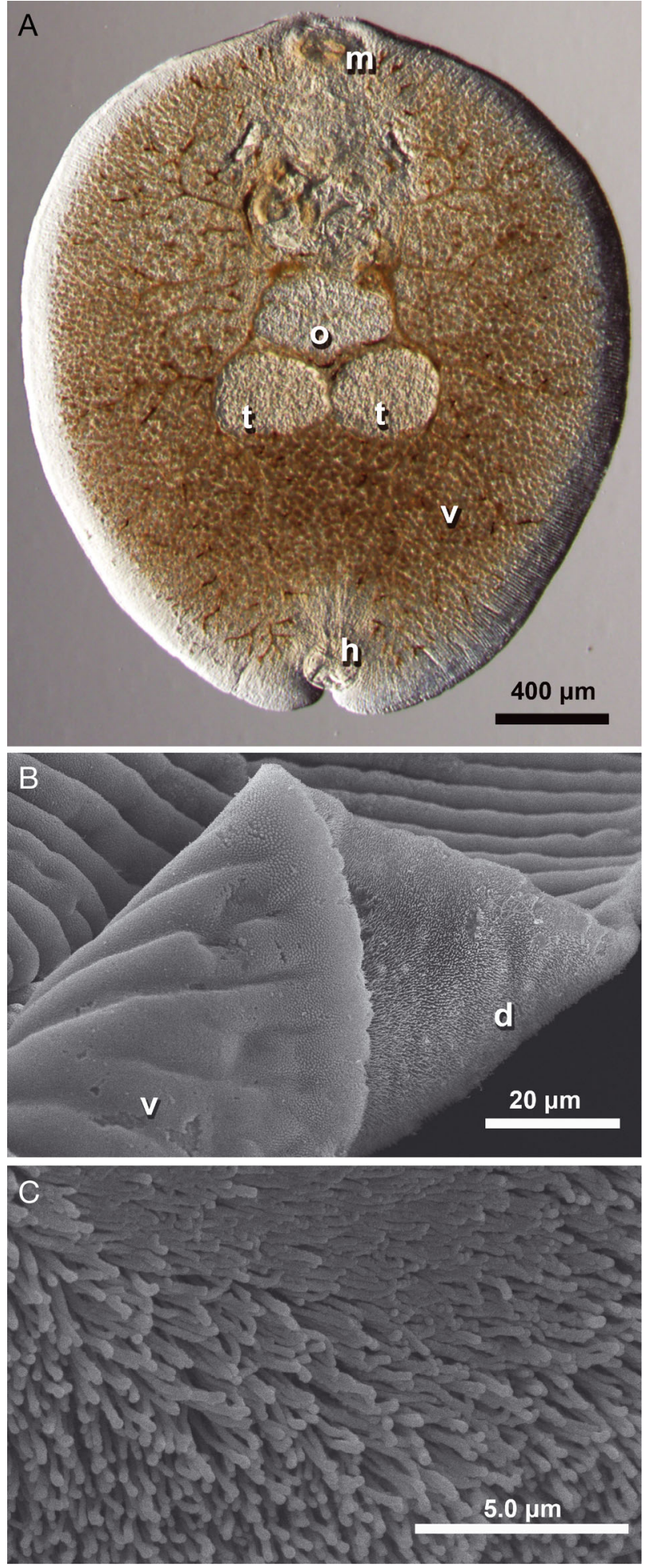

Fig. 5. Dermophthirioides pristidis collected from smalltooth sawfish Pristis pectinata in south Florida. (A) Photomicrograph of ventral surface; $m$, mouth; $o_{\text {, ovary; }}$, testis; $v$, vitellarium; h, haptor (attachment organ). (B) Scanning electron micrograph of folded body margin near haptor; $d$, dorsal surface; v, ventral surface. (C) Scanning electron micrograph of densely papillated dorsal surface 

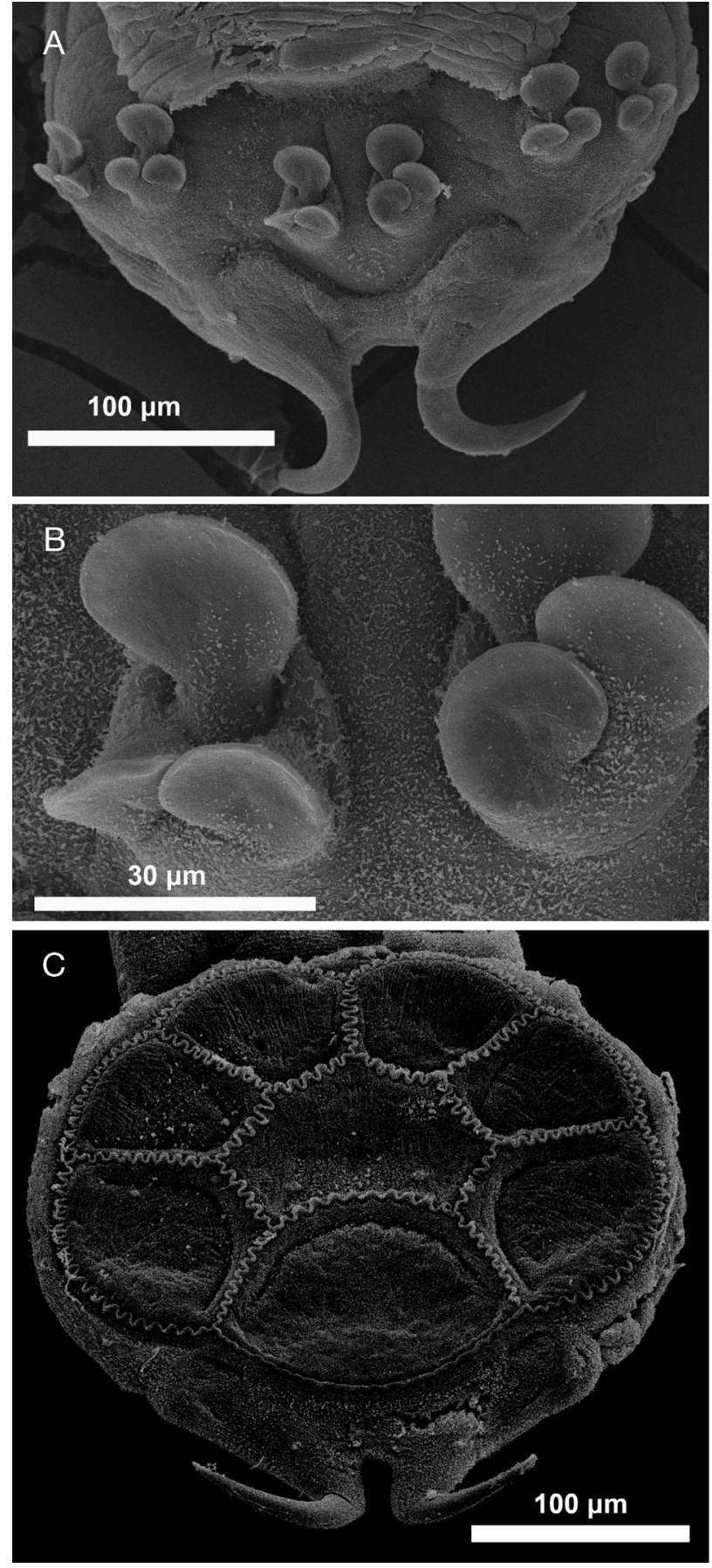

Fig. 6. Scanning electron micrographs of the haptor (attachment organ) of Neoheterocotyle inpristi collected from the gill of smalltooth sawfish Pristis pectinata. (A) Dorsal surface. (B) Details of dorsal haptoral accessory sclerites. (C) Ventral surface

A blood fluke, Aporocotylidae sp. (Fig. 8), found in rinsings of the heart, remains undescribed.

An observed lesion associated with a parasitic infection can be related to the attachment or feeding

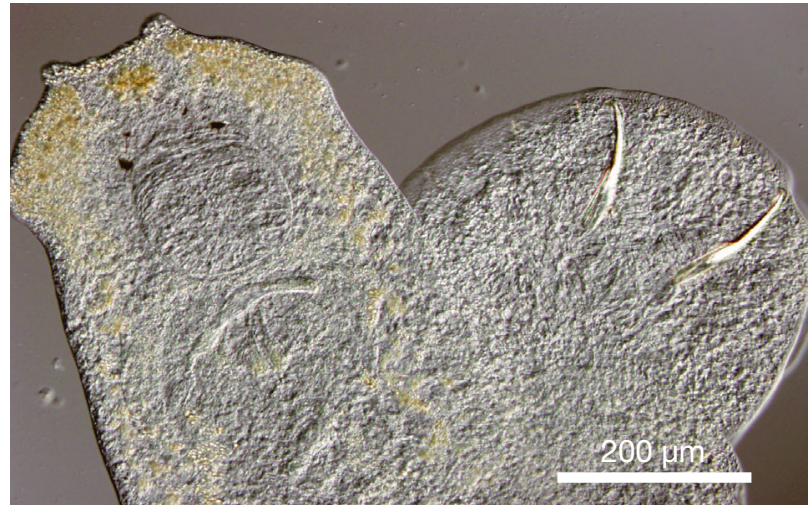

Fig. 7. Photomicrograph of a fresh specimen of Mycteronastes caalusi taken from the olfactory organ of a smalltooth sawfish Pristis pectinata. Specimen is folded so that the anterior portion of the body (left side of image) overlays the posterior portion (right side of image)

activity of the parasite. Different parasites feed on different tissue components. For example, leeches feed on blood, whereas monogenoids found in this study feed on the epidermis, principally epithelial cells or mucous (goblet) cells. Grossly visible parasite-associated lesions were rare in our samples, and only the leech Branchellion torpedinis was associated with a significant lesion. The bluish patches of skin sometimes associated with infections by Dermophthirioides pristidis in our samples are similar to those caused by its relative Dermopthirius penneri Benz, 1987 on the skin of the blacktip shark Carcharhinus limbatus (Müller \& Henle, 1839). Bullard et al. (2000) described these lesions in detail and concluded that they were not severe or debilitating unless environmental conditions were such that the parasite popu-

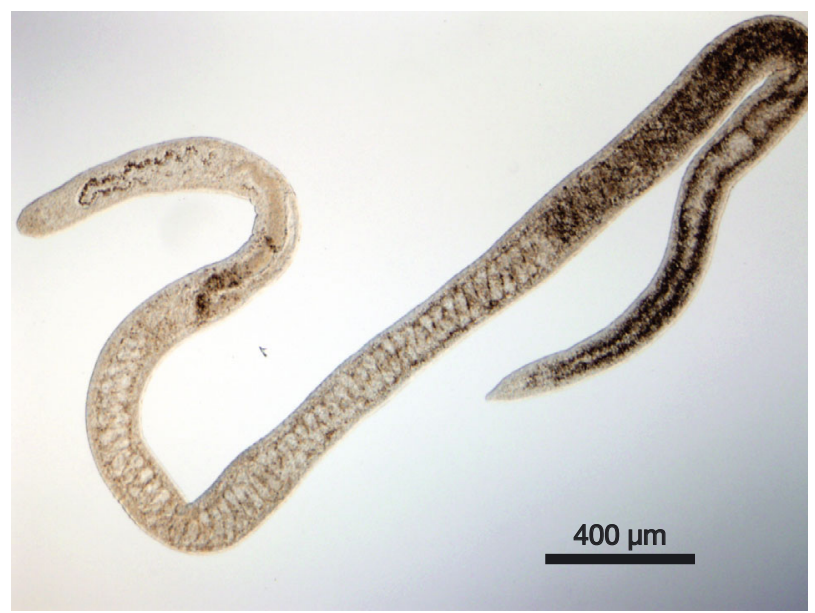

Fig. 8. Photomicrograph of a fresh specimen of an undescribed blood fluke (Aporocotylidae) taken from the heart of a smalltooth sawfish Pristis pectinata 
lation on the host increased to the point that the lesions could become pathogenic. Like other microbothriids, Dermophthirioides pristidis is alleged to threaten the health of its captive host (Cheung \& Nigrelli 1983), and other monogenoids are known to reach pathogenic intensities in aquariums while likely remaining benign in wild host populations (Benz \& Bullard 2004). In contrast, B. torpedinis, because it is a blood-feeding ectoparasite that must pierce the epidermis (which is nonvascular in elasmobranchs) to reach the vascular portions of the stratum compactum (deep dermis), causes ulcerative lesions even if only one leech is present. Marancik et al. (2012) showed that a single specimen of the leech could be lethal in the yellow stingray Urobatis jamaicensis (Cuvier, 1816) under laboratory conditions.

While we did not detect a leech when we first noticed the lesioned clasper of one host specimen, $B$. torpedinis apparently can temporarily hide in a body cavity, especially the orobranchial chamber and possibly the cloaca (A. D. Dove pers. comm.). Further, these leeches are expected to move off and back onto the host during their life cycle (Benz \& Bullard 2004), so additional leeches may have contributed to the lesion if the clasper is a preferred site of infection (but see Marancik et al. 2012, who suggest that this species may form a more lasting association with a given host).

The host-specific parasite species of smalltooth sawfish are of particular interest because they are likely to be endangered, as is the sawfish itself. Parasites dependent on a single host species are theoretically more vulnerable to extinction than are generalist parasites (Koh et al. 2004, Dunn et al. 2009). Given the empirically demonstrable success of high host specificity as an adaptive strategy, this might be a flawed assumption when applied to the entirety of evolutionary history, but it is probably valid at least in the context of the ongoing Holocene (Anthropocene) extinction event, during which ancient and widely distributed host lineages such as the Elasmobranchii are experiencing unprecedented anthropogenic threats (Strona 2015). In fact, parasites with high host specificity may be even more vulnerable to extinction than their hosts, in part because parasite transmission rates may drop below critical minima when host abundance is low (Dunn et al. 2009, Moir et al. 2010). Many of the parasitic taxa reported here, such as Pandarus sp. and B. torpedinis, have been reported from other host species, and some, like a free-swimming juvenile specimen of Livoneca sp., are likely transient and may even qualify as incidental. Mycteronastes caalusi and the undescribed aporocotylid, however, are probably specific to smalltooth sawfish (Benz \& Bullard 2004, Orélis-Ribeiro et al. 2014, S. A. Bullard pers. obs.). Notably, D. pristidis and N. inpristi, both putative specialists on smalltooth sawfish, are already known to form niche pairings with distinct but related species of monogenoids reported from largetooth sawfish Pristis pristis (Linnaeus, 1758) (sensu Faria et al. 2013) and dwarf sawfish P. clavata Garman, 1906 collected in Australia. Dermophthirioides pristidis and Dermopristis paradoxus Kearn, Whittington \& Evans-Gowing, 2010 infect the skin of smalltooth sawfish and largetooth sawfish, respectively (Kearn et al. 2010), and N. inpristi and N. darwinensis Chisholm \& Whittington, 2000 infect the gills of smalltooth sawfish and dwarf sawfish, respectively (Chisholm \& Whittington 2000).

Among the parasites observed in our surveys and based on available evidence, Dermophthirioides pristidis could be a useful biological indicator. Firstly, it attaches externally, a prerequisite for nonlethal sampling of the host. Further, at maturity it is large enough (reaching $>5 \mathrm{~mm}$ diameter) to be observed by experienced analysts without magnification. It is also likely to be exclusively a parasite of smalltooth sawfish because (1) it has yet to be reported from another host and (2) a high degree of host specificity is to be expected among microbothriids (Benz \& Bullard 2004). Finally, it is relatively abundant and so may better support statistically robust baseline data sets than many species observed less frequently in our samples.

Seitz \& Poulakis (2002) noted that a variety of independent data sets strongly suggest that the population and geographic range of the smalltooth sawfish diminished during the 20th century, but they also showed that a relatively healthy breeding population still uses our sampling area as a nursery. So, any successful conservation efforts will likely result in the dispersal of individuals from southwestern Florida to other localities in the species' historic range, and they could vector Dermophthirioides pristidis. The absence of hemorrhagic lesions caused by $D$. pristidis in combination with the relatively high prevalence and moderate intensities of this monogenoid in our samples suggests an ecosystem in healthy equilibrium from the perspectives of host and parasite. Thus, our data for $D$. pristidis could comprise a baseline for relatively healthy populations of smalltooth sawfish occupying suitable habitats, a useful reference point for gauging the health and stability of future colony populations and possibly for identifying systemic problems before ecological tipping points are passed. 
Season and host size affected prevalence of $D$. pristidis, and size also explained some variation in intensity of infection. A correlation between host size and prevalence and intensity has been shown for other marine fishes (Rohde et al. 1995). Although D. pristidis was present year-round, our findings suggest an annual population decline in summer and fall and a proliferation in spring. A possible source of noise in our prevalence and intensity data is our practice of removing $D$. pristidis from hosts. Thus, our research vessel often served as a sort of anthropogenic cleaning station, and we could have artificially decreased prevalence and intensity in recaptured hosts. Yet only 3 hosts were infected at first capture and then uninfected at recapture. Further, we found that prevalence and intensity were on average higher in larger hosts, a trend that should have been muted if our removal of parasites from hosts when they were smaller reduced the probability of infection when they were recaptured later, at a larger size.

The tolerance of $D$. pristidis of low salinities has not been investigated, but it may well be lower than that of its host, a possibility relevant to host conservation. The summer-fall decline in $D$. pristidis populations corresponds with the rainy season in south Florida (June to November), a period during which marked drops in salinity can influence the movements of smalltooth sawfish within the nursery, but they remain within it (Poulakis et al. 2011, 2013). Parasites have been called ecological puppeteers because their impacts on individual hosts' health and behavior can be profound at the ecosystem (collective) level (Dougherty et al. 2016), and the possibility that infection by $D$. pristidis could influence host movements in the Charlotte Harbor estuarine system is intriguing. Poulakis et al. (2011) suggested that the tendency for juvenile smalltooth sawfish to remain in place during periods of high freshwater flow might be an adaptive strategy for avoiding predators and competitors, but they did not consider whether low salinity might have a prophylactic effect on ectoparasites. If periods of low salinity are necessary for the control of populations of $D$. pristidis, this could be an important consideration in management of river systems with damregulated flow rates. Alterations in freshwater flow due to climate change could also be a factor in the stability of this host-parasite relationship.

Moving forward, we intend to retain parasitology as a component of smalltooth sawfish monitoring in southwest Florida. We will continue obtaining prevalence and intensity data for $D$. pristidis to further develop a multiyear baseline data set that may be useful in conservation efforts. Representative specimens of
D. pristidis will be preserved in $95 \%$ ethanol to facilitate future population-genetic studies that could provide information on the movements of smalltooth sawfish as they disperse into localities from which they had once been extirpated. Taxonomic descriptions of 2 species new to science are either complete (Kritsky et al. 2017) or in preparation, and additional investigations may reveal other new species. The lack of basic information on the parasites of smalltooth sawfish suggests that future research on this host might benefit from adoption of the core philosophy behind Windsor's (1995) slogan 'Equal Rights for Parasites', i.e. that parasites matter in conservation biology. These parasites are valuable components of biological diversity, they are potentially useful as tools in host conservation, and they likely have a complex relationship with host health that goes beyond pathogenicity.

Acknowledgements. We thank Alistair Dove (Georgia Aquarium), who generously provided insight and shared his observations on the behavior of Branchellion torpedinis. Robin Grunwald, of the Fish and Wildlife Research Institute (FWRI) library, provided assistance obtaining references. Bland Crowder and Theresa Cody improved earlier versions of the manuscript, as did Clark Gray, who also played a critical role in electron microscopy by preparing specimens and assisting with the production of micrographs. Maki Tabuchi assisted with parasite sampling during necropsies, as did Yasunari Kiryu, who additionally took the photograph used for Fig. 1. Our smalltooth sawfish research is ongoing and has been supported primarily by funding from the US Department of Commerce (DOC), National Oceanic and Atmospheric Administration's (NOAA) National Marine Fisheries Service through Section 6 (Cooperation with the States) of the US Endangered Species Act under the following grant awards to the Florida Fish and Wildlife Conservation Commission from both NOAA (NA06NMF4720032, NA10NMF4720032, and NA13NMF4720047) and the National Fish and Wildlife Foundation (NFWF; 2003-0206-008 and 2004-0012008). Funding for collection, processing, and identification of parasites was provided in part to FWRI by the US Department of the Interior (DOI) US Fish and Wildlife Service (USFWS) Federal Sportfish Restoration Grants F-72 9-16, F12AF00878, F13AF00529, F14AF00955, F15AF00893, and F16AF00544. This is also a contribution of the Southeastern Cooperative Fish Parasite and Disease Project (Auburn University). Preliminary aspects of this work were presented as part of the symposium 'Biology and Ecology of Sawfishes' at the 2016 annual meeting of the American Elasmobranch Society, which was supported by funding from the Save Our Seas Foundation, Disney Conservation Fund, and the American Elasmobranch Society. Statements, findings, conclusions, and recommendations are those of the authors and do not necessarily reflect the views or policies of the DOC, NOAA, DOI, USFWS, or the NFWF. Mention of trade names or commercial products does not constitute their endorsement by the US government, the State of Florida, or the NFWF. This research was conducted under Endangered Species Permit numbers 1475 and 15802 (FWC) issued by the National Marine Fisheries Service. 


\section{LITERATURE CITED}

Bakenhaster MD (2004) External morphological features of mancas of four parasitic isopod species (Cymothoidae) in the northern Gulf of Mexico. MSc thesis, University of Southern Mississippi, Gulf Coast Research Laboratory, Ocean Springs, MS

Benz GW, Bullard SA (2004) Metazoan parasites and associates of chondrichthyans with emphasis on taxa harmful to captive hosts. In: Smith M, Warmolts D, Thoney DA, Hueter R (eds) Elasmobranch husbandry manual: captive care of sharks, rays, and their relatives. Ohio Biological Survey, Columbus, OH, p 325-416

Bray RA, Cribb TH (2003) The digeneans of elasmobranchs - distribution and evolutionary significance. In: Tome I, Combes C, Jourdane J (eds) Taxonomy, ecology and evolution of metazoan parasites. (Livre homage à Louis Euzet). University of Perpignan Press, Perpignan, p 67-96

Bruce NL (1990) The genera Catoessa, Elthusa, Enispa, Ichthyoxenus, Idusa, Lovoneca and Norileca n.gen. (Isopoda, Cymothoidae), crustacean parasites of marine fishes, with descriptions of eastern Australian species. Rec Aust Mus 42:247-300

Brusca RC (1978) Studies on the cymothoid fish symbionts of the eastern Pacific (Isopoda, Cymothoidae) I. Biology of Nerocila californica. Crustaceana 34:141-153

Brusca RC (1981) A monograph on the Isopoda Cymothoidae (Crustacea) of the eastern Pacific. Zool J Linn Soc 73:117-199

Bullard SA, Frasca S Jr, Benz GW (2000) Skin lesions caused by Dermophthirius penneri (Monogenea: Microbothriidae) on wild-caught blacktip sharks (Carcharhinus limbatus). J Parasitol 86:618-622

Bunkley-Williams L, Williams EH Jr, Bashirullah AKM (1998) Some isopods associated with Venezuelan fishes. Caribb Mar Stud 6:27-30

Cheung PJ, Nigrelli RF (1983) Dermophthirioides pristidis n. gen., n. sp. (Microbothriidae) from the skin and Neoheterocotyle ruggierii $\mathrm{n}$. $\mathrm{sp}$. (Monocotylidae) from the gills of the smalltooth sawfish, Pristis pectinata. Trans Am Microsc Soc 102:366-370

Chisholm LA (1994) A review of Neoheterocotyle (Monogenea: Monocotylidae). J Parasitol 80:960-965

Chisholm LA, Whittington ID (2000) A new species of Neoheterocotyle Hargis, 1955 (Monogenea: Monocotylidae) from the gills of Pristis clavata Garman (Pristidae) from Darwin, Australia. Syst Parasitol 46:93-98

Cressey R (1967) Revision of the family Pandaridae (Copepoda: Caligoida). Proc US Natl Mus 121, No. 3570. Smithsonian Institution, Washington, DC

*Dobson A, Lafferty KD, Kuris AM, Hechinger RF, Jetz W (2008) Homage to Linnaeus: How many parasites? How many hosts? Proc Natl Acad Sci USA 105:11482-11489

Wougherty ER, Carlson CJ, Bueno VM, Burgio KR and others (2016) Paradigms for parasite conservation. Conserv Biol 30:724-733

Dunn RR, Harris NC, Colwell RK, Koh LP, Sodhi NS (2009) The sixth mass coextinction: Are most endangered species parasites and mutualists? Proc R Soc B 276: 3037-3045

Faria VV, McDavitt MT, Charvet P, Wiley TR, Simpfendorfer CA, Naylor GJP (2013) Species delineation and global population structure of Critically Endangered sawfishes (Pristidae). Zool J Linn Soc 167:136-164
Hargis WJ Jr (1955) Monogenetic trematodes of Gulf of Mexico fishes. Part V. The superfamily Capsaloidea. Trans Am Microsc Soc 74:203-225

Hutton RF (1964) A second list of parasites from marine and coastal animals of Florida. Trans Am Microsc Soc 83: 439-477

*ICZN (International Commission on Zoological Nomenclature) (1996) Opinion 1849. Livoneca Leach, 1818 (Crustacea, Isopoda): the original spelling confirmed as correct, and the spelling Lironeca rejected. Bull Zool Nomencl 53:210-212

* Johnson PTJ, Preston DL, Hoverman JT, LaFonte BE (2013) Host and parasite diversity jointly control disease risk in complex communities. Proc Natl Acad Sci USA 110: 16916-16921

Kearn GC, Whittington ID, Evans-Gowing R (2010) A new genus and new species of microbothriid monogenean (Platyhelminthes) with a functionally enigmatic reproductive system, parasitic on the skin and mouth lining of the largetooth sawfish, Pristis microdon, in Australia. Acta Parasitol 55:115-122

Koh LP, Dunn RR, Sodhi NS, Colwell RK, Proctor HC, Smith VS (2004) Species coextinctions and the biodiversity crisis. Science 305:1632-1634

Kritsky DC, Bullard SA, Bakenhaster MD, Scharer RM, Poulakis GR (2017) Resurrection of Mycteronastes (Monogenoidea: Monocotylidae), with description of Mycteronastes caalusi n. sp. from olfactory sacs of the smalltooth sawfish, Pristis pectinata (Pristiformes: Pristidae), in the Gulf of Mexico off Florida. J Parasitol 103:477-485

*Marancik DP, Dove AD, Camus AC (2012) Experimental infection of yellow stingrays Urobatis jamaicensis with the marine leech Branchellion torpedinis. Dis Aquat Org 101:51-60

* Marcogliese DJ (2005) Parasites of the superorganism: Are they indicators of ecosystem health? Int J Parasitol 35: 705-716

*Moir ML, Vesk PA, Brennan KEC, Keith DA, Hughes L, McCarthy MA (2010) Current constraints and future directions in estimating coextinction. Conserv Biol 24: 682-690

*Moreira PS, Sadowsky V (1978) An annotated bibliography of parasitic Isopoda (Crustacea) of Chondrichthyes. Bol Inst Oceanogr 27:95-152

NMFS (United States National Marine Fisheries Service) (2003) Endangered and threatened species; final endangered status of a distinct population segment of smalltooth sawfish (Pristis pectinata) in the United States. Fed Regist 68:15674-15680

\% Orélis-Ribeiro R, Arias CR, Halanych KM, Cribb TH, Bullard SA (2014) Chapter One - Diversity and ancestry of flatworms infecting blood of nontetrapod craniates 'fishes'. Adv Parasitol 85:1-64

Poulakis GR, Stevens PW, Timmers AA, Stafford CJ, Curtis C, Tringali MD, Bakenhaster MD (2010) Distribution, habitat use, and movements of juvenile smalltooth sawfish, Pristis pectinata, in the Charlotte Harbor estuarine system, Florida. Final Report to the National Marine Fisheries Service for Award NA06NMF4720032. FWRI File-code F2616-06-09-F

* Poulakis GR, Stevens PW, Timmers AA, Wiley TR, Simpfendorfer CA (2011) Abiotic affinities and spatiotemporal distribution of the endangered smalltooth sawfish, Pristis pectinata, in a south-western Florida nursery. Mar Freshw Res 62:1165-1177 
Poulakis GR, Stevens PW, Timmers AA, Stafford CJ, Simpfendorfer CA (2013) Movements of juvenile endangered smalltooth sawfish, Pristis pectinata, in an estuarine river system: use of non-main-stem river habitats and lagged responses to freshwater inflow-related changes. Environ Biol Fishes 96:763-778

Poynton SL, Campbell TW, Palm HW (1997) Skin lesions in captive lemon sharks Negaprion brevirostris (Carcharhinidae) associated with the monogenean Neodermophthirius harkemai Price, 1963 (Microbothriidae). Dis Aquat Org 31:29-33

Richardson H (1905) A monograph on the isopods of North America. Bulletin of the United States National Museum No. 54. Smithsonian Institution, Washington, DC

Rohde K, Hayward C, Heap M (1995) Aspects of the ecology of metazoan ectoparasites of marine fishes. Int J Parasitol 25:945-970

Sawyer RT, Lawler AR, Overstreet RM (1975) Marine leeches of the eastern United States and the Gulf of Mexico with a key to the species. J Nat Hist 9:633-667

Seitz JC, Poulakis GR (2002) Recent occurrence of sawfishes (Elasmobranchiomorphi: Pristidae) along the southwest coast of Florida (USA). Fla Sci 65:256-266

Strona G (2015) Past, present and future of host-parasite co-

Editorial responsibility: Dean Grubbs (Guest Editor),

St. Teresa, Florida, USA extinctions. Int J Parasitol Parasites Wildl 4:431-441

* Sures B (2003) Accumulation of heavy metals by intestinal helminths in fish: an overview and perspective. Parasitology 126:S53-S60

van Oijen MJP, Faria VV, McDavitt MT (2007) The curious holotype of Pristis dubius Bleeker, 1852 and the unravelling of Bleeker's sawfish taxonomy. Raffles Bull Zool $17: 37-49$

*Whiteman NK, Parker PG (2005) Using parasites to infer host population history: a new rationale for parasite conservation. Anim Conserv 8:175-181

*Williams EH Jr, Bowman TE (1994) Lironeca Leach, 1818 (Crustacea, Isopoda): proposed conservation as the correct original spelling. Bull Zool Nomencl 51:224-226

Windsor DA (1995) Equal rights for parasites. Conserv Biol 9:1-2

Windsor DA (1998) Most of the species on Earth are parasites. Int J Parasitol 28:1939-1941

WWood CL, Johnson PTJ (2015) A world without parasites: exploring the hidden ecology of infection. Front Ecol Environ 13:425-434

Y Young JM, Frasca S Jr, Gruber SH, Benz GW (2013) Monogenoid infection of neonatal and older juvenile lemon sharks, Negaprion brevirostris (Carcharhinidae), in a shark nursery. J Parasitol 99:1151-1154

Submitted: October 13, 2016; Accepted: September 19, 2017 Proofs received from author(s): December 14, 2017 